\title{
NOTICIAS
}

\section{Acceso para todos: la comunidad internacional con trabajo en VIH/SIDA se reunió en Bangkok}

Con la asistencia de más de 15 mil delegados de 160 países de todos los rincones del globo, durante la semana del 11 al 16 de julio se llevó a cabo la XV Conferencia Internacional de SIDA, en Bangkok, la capital de Tailandia, y lugar de una de las primeras historias de éxito en el combate a la epidemia.

La conferencia de Bangkok ocurre en un contexto cada vez más dominado por la urgente necesidad de incrementar el acceso a los medicamentos (antirretrovirales) a todos aquellos que los necesitan. Los datos presentados en la conferencia por el Programa Conjunto de las Naciones Unidas para VIH/SIDA (ONUSIDA), señalan que para finales de 2003 había en el mundo cerca de 38 millones de personas que viven con el virus, la inmensa mayoría de ellos en países de ingresos bajos y medios.

En esta tónica, el lema de la Conferencia, "Acceso para todos" (Access for all), fue un reflejo de esta preocupación, y fue más allá al discutirse la necesidad de incrementar el acceso también a intervenciones de prevención y a mecanismos que permitan paliar los efectos de la epidemia más allá de la salud.

Incrementar el acceso a tratamiento antirretroviral es un reto que implica incrementar el porcentaje de seropositivos que conocen su estado serológico, hacer asequibles los medicamentos y contar con sistemas de salud con capacidad para proveer de atención.

La Conferencia fue un espacio para el debate: mientras se llevaban a cabo presentaciones sobre los recursos que se han movilizado para hacer frente a la epidemia, y se producían anuncios sobre nuevos compromisos de recursos (la Fundación Gates, por ejemplo, ofreció incrementar su aportación al Fondo Global en 50 millones de dólares), los activistas presentes reclamaban al presidente George Bush los obstáculos que los Estados Unidos de América han puesto a los países en desarrollo para incrementar la producción de medicamentos genéricos. Hubo un llamado a unir fuerzas entre países para conseguir medicamentos asequibles y hacer uso de los acuerdos de comercio, que están pasando inadvertidos. En la línea de los genéricos, Brasil, Tailandia, Nigeria, Rusia, Ucrania y China anunciaron la formación de una alianza para incrementar la producción de antirretrovirales genéricos.

Por lo que se refiere a la prevención, los debates más importantes giraron alrededor del concepto $\mathrm{ABC}$ (abstinencia, fidelidad y uso de condón), enfoque que en algunos casos ha destacado la abstinencia y fidelidad, sin considerar que para muchas mujeres la primera no es algo que pueden decidir y la segunda no es ga- rantía si sus parejas, como ocurre en muchos casos, tienen otras relaciones.

No obstante, la presión ejercida por la administración Bush ha conseguido que se incremente el número de programas que utilizan la promoción de la abstinencia como principal herramienta de prevención, aun cuando los resultados que se han mostrado no sólo no muestran un efecto positivo, sino que podrían disminuir el uso de condón.

En el tema de prevención, en un contexto de carencia de evidencia sobre lo que funciona, abundaron los mensajes retóricos acerca de que ya se sabe qué es lo que funciona y lo que se necesita son recursos para hacerlo. Lamentablemente, en esta Conferencia no abundaron los ejemplos de qué es lo que funciona.

A continuación se presenta un breve recuento de las presentaciones realizadas en cada una de las áreas en las que se dividieron los temas de la Conferencia.

Ciencia básica, investigación clínica y tratamiento

De los trabajos presentados en ciencia básica, resaltaron dos temas. Por un lado, el desarrollo de formulaciones farmacológicas diseñadas para actuar sobre la célula huésped, y no sobre el virus. El otro tema importante fue sobre los avances en el desarrollo de la tan esperada vacuna y los obstáculos a los que se están enfrentando los científicos para su 
desarrollo. Las infecciones con más de un tipo de virus, las mutaciones, la migración y el crecimiento en la cobertura con tratamiento antirretroviral son factores que están afectando el desarrollo de la vacuna, al generar tantas recombinaciones de cadenas virales que complican la posibilidad de una vacuna que haga frente a todas o, si se hace para una sola, que pueda tener una efectividad aceptable.

En el área clínica hubo buenas y malas noticias. Por el lado de las malas se presentaron estudios en los cuales se mostró que el uso de nevirapina para la prevención de la transmisión vertical, si bien es efectiva para evitar la infección de los bebés, incrementa la probabilidad de mutaciones resistentes en las madres, lo que complica su tratamiento después del alumbramiento. De esta forma, un medicamento barato y efectivo puede tener que ser descartado, dados sus efectos posteriores en las madres. Por el lado positivo, dos buenas noticias: por un lado, se presentaron tecnologías mucho más baratas para el monitoreo de la atención, disminuyendo el costo del conteo de CD4 y la carga viral hasta a dos dólares, muy por debajo de los costos actuales. Por otra parte, en términos de las mejores combinaciones de medicamentos, en un contexto en el que hay disponibles alrededor de 1333 combinaciones, se presentaron resultados que muestran que los esquemas sugeridos como parte de la iniciativa de OMS "3 millones para 2005" (que busca que para finales del año 2005 haya en los países en desarrollo al menos tres millones de personas que reciben terapia antirretroviral), resultaron ser de las combinaciones con mayor sobrevida, al mismo tiempo que son más baratos. De esta forma, al presentar el resumen en esta área, el comentario final en la Conferencia fue que es una falacia que los medicamentos más caros son, necesariamente, mejores.

\section{Epidemiología y prevención}

En esta área se discutieron los avances en estudios en dos grandes grupos: por un lado, los biomédicos, referidos a los estudios para mostrar la efectividad de intervenciones médicas para frenar la transmisión y por el otro, los resultados de los estudios sobre comportamientos.

En el primer grupo, la conferencia subrayó ensayos clínicos de tercera fase que dan la esperanza de que, dentro de cinco años, podamos contar con microbicidas vaginales, el uso del diafragma como método de barrera, la circuncisión masculina, el tratamiento de herpes simplex (HSV2), y antirretrovirales (bajo la idea de que con menos carga viral las personas son menos propicias a transmitir el virus).

En el área de los estudios sobre comportamientos, se presentaron algunos que buscaron identificar las características individuales que incrementan la probabilidad de prácticas de riesgo. Los resultados presentados mostraron una mayor vulnerabilidad entre: mujeres jóvenes, mujeres que son parejas de hombres que tienen sexo con hombres, y usuarios de drogas inyectables. En estos grupos de población es necesario el desarrollo de estrategias novedosas e imaginativas de prevención.

Como una herramienta para conocer la incidencia de la enfermedad, se ha seguido avanzando en el uso de lo que se conoce como pruebas de Elisa detuned, es decir, con una sensibilidad menor a las pruebas actualmente disponibles, y que permiten llevar a cabo estimaciones de las infecciones recientes, lo que utilizado dentro de los esquemas de vigilancia epidemiológica podría permitir un mayor conocimiento de la tendencia actual de la epidemia en cuanto a los grupos en donde es prioritaria la prevención.

Un tema que resaltó durante la conferencia fue la importancia de contar con intervenciones efectivas en los países que parecen estar en las fronteras de una epidemia de mayores proporciones, en particular la región de Asia Pacífico, con países como la India, en la que la implantación en estos momentos de intervenciones de prevención puede evitar millones de nuevos casos de VIH en los próximos años.

\section{Asuntos sociales y económicos, ejecución} de programas y politicas

Probablemente el tema medular en cuanto a los aspectos sociales y económicos fue la discusión sobre la necesidad de contextualizar las intervenciones de VIH/SIDA en la situación de pobreza, género, edad, preferencia sexual y carencia de derechos por otras condiciones, así como el estigma y la discriminación relacionados con el VIH, situaciones presentes para la mayor parte de los afectados. La prevención y la atención de las personas que viven con el VIH/ SIDA no puede darse fuera de este contexto.

Sobresalieron las presentaciones sobre proyectos de micro-créditos y otras intervenciones enfocadas al combate a la pobreza como una forma de paliar los efectos de la epidemia en las comunidades. No obstante, el consenso es que aún hace falta mucho trabajo en esta dirección. De parte de las comunidades afectadas se escuchó el reclamo contra el concepto de trabajadores de salud voluntarios, que no tienen sentido en países en los que hay una lucha cotidiana por la sobrevivencia en la pobreza.

Se habló de la necesidad de que para la próxima Conferencia, en Toronto, se presenten más resultados en este tipo de intervenciones, así como de incrementar la presencia de las poblaciones más afectadas, que se escuche su voz en las presentaciones.

Siguiendo el llamado de ONUSIDA, las discusiones en cuanto a la ejecución de políticas insistieron en 
la importancia de lo que se ha llamado los tres unos: un programa nacional, un marco nacional de acción y un marco de monitoreo y evaluación nacional, es decir, coordinación para hacer frente a la epidemia. Por otra parte, se destacó la importancia de integrar a las comunidades afectadas en el desarrollo e implantación de políticas, así como en la necesidad de reforzar la formación de recursos humanos

\section{Conclusiones}

La Conferencia evidenció que el movimiento contra el SIDA sigue siendo diverso y un espacio de debate. En estos 20 años hemos avanzado sobre todo en aspectos técnicos (como los medicamentos antirretrovirales); no obstante, estos mismos avances nos han llevado al punto de que no podemos seguir ignorando los factores que han impedido una respuesta efectiva a la epidemia como la inequidad -entre países pobres y ricos, hombres y mujeres, personas seropositivas y seronegativas, entre otros. Un paso importante para avanzar en esta dirección fue repetido como consenso en la clausura: es imprescindible que las políticas y los programas en VIH se inscriban en las realidades cotidianas de las personas infectadas, afectadas y vulnerables, y se elaboren con su participación activa, y no agendas ideológicas de los países u organizaciones donantes o gobiernos nacionales.

Asimismo, es indispensable incrementar la generación de evidencia obtenida de forma rigurosa acerca de lo que funciona, tanto en prevención como en atención. Es importante por lo tanto hacer un uso eficiente de los recursos, así como entregar cuentas claras a la sociedad.

Juan Pablo Gutiérrez,Tamil Kendall, M irka N egroni, Sergio Bautista. Instituto Nacional de Salud Pública, Centro Colaborador ONUSIDA-INSP. 